\title{
Occurrence of Piperidine-2,6-dicarboxylic acid (trans) in a Red Alga, Porphyra tenera
}

\author{
Hiroshi Kawauchi, ${ }^{* 1}$ Shuzi TukazIma, ${ }^{* 1}$ Shizuyuki Ota, ${ }^{* 1}$ and Asao MUrai*2 \\ (Received June 12, 1978)
}

\begin{abstract}
Porphyra tenera, an edible red alga, was found to contain a new acidic imino acid $\left(\mathrm{C}_{7} \mathrm{H}_{11} \mathrm{NO}_{4}\right)$. This compound named teneraic acid is obtained from an alcoholic extract.

The chemical structure of teneraic acid was determined to be piperidine-2,6-dicarboxylic acid by means of NMR, Mass, and IR spectrometric studies and by chemical synthesis. The configuration of the compound was proved to be a trans form by ORD spectrometry.
\end{abstract}

Porphyra tenera has been extensively investigated in termes of amino acid composition and the seasonal variation of the amino acids. No unusual amino acid, however, has been reported. In our survey on amino acids in various marine algae, it was recognized that an alcoholic extract of the alga contained a ninhydrin positive component, which migrated to the anode faster than aspartic acid at $\mathrm{pH} 3.1$. The component was named teneraic acid.

This communication reports the isolation of teneraic acid, and the elucidation of the chemical structure and the partial configuration of the acid.

\section{Experimental}

\section{Isolation of Teneraic Acid}

The alga (1 kg) was collected in Okkirai Bay in December. The amino acid extract was initially prepared by the procedure as previously described for chordarine ${ }^{11}$. Acidic amino acids were adsorbed on a column $(3 \times 38 \mathrm{~cm})$ of Dowex $1 \times 8$ in the acetate form. Elution was performed by a gradient of $0.2-2 \mathrm{~N}$ acetic acid. Every fraction was tested by paper electrophoresis at $400 \mathrm{~V}$, pH 3.1. Ammonium tenerate was crystallized from aqueous ethanol.

Preparation of Piperidine-2,6-dicarboxylic Acid

Piperidine-2,6-dicarboxylic acid was prepared by two different methods. (1): Pyridine-2,6-dicarboxylic acid was hydrogenated with platinium black in $50 \%$ acetic acid. ${ }^{21}$ The product was crystallized from aqueous ethanol. (2): Piperidine-2,6-di carboxylic acid was prepared by an imination reaction of $\alpha, \alpha^{\prime}$-dibromopimeric acid $(10 \mathrm{~g})$ with ammonium carbonate $(25 \mathrm{~g})$ in $70 \%$ ethanol $(700 \mathrm{~m} l)$ for two weeks at room temperature. The remaining $\alpha, \alpha^{\prime}$-dibromopimeric acid was extracted with ether after acidifying the reaction mixture. The products were purified with ion exchange chromatography on Dowex $50 \mathrm{~W} \times 8(3 \times 120 \mathrm{~cm})$ in the pyridinium form, using $0.2 \mathrm{M}$ pyridinium acetate, pH 3.1 as elution buffer. The isomers of piperidine-2,6-dicarboxylic acid were separated by fractional crystallization using aqueous ethanol.

\section{Spectrophotometric Studies}

Mass spectra were obtained with a Jeol model, LMG-06H. Samples were introduced with a direct inlet probe. NMR spectra were taken with a Jeol model JNM-PMX in $\mathrm{D}_{2} \mathrm{O}$ with DSS as standard. Infrared spectra were measured with a Jasco model, IR-AI in $\mathrm{KBr}$ disc. ORD spectra were taken with a Jasco model, ORD-UV-5 in $\mathrm{H}_{2} \mathrm{O}$.

\section{Results and Discussion}

\section{Isolation}

Paper electrophoresis revealed that glutamic acid was eluted in fractions 18 to $28(15 \mathrm{~m} / /$ tube), aspartic acid in fractions 24 to 38 , and teneraic acid in fractions 48 to 94 by a gradient elution of acetic acid from the anion exchanger. After concentration in vacuo, ammonium tenerate was crystallized from aqueous ethanol. The yield was $120 \mathrm{mg}$ of colorless needles, melting at 217 -

*1 School of Fisheries Sciences, Kitasato University, Sanriku, Iwate 022-01 （川内浩司・塚島修二 ·太田静 行: 北里大水産).

*2 The Central Research Laboratory of Ajinomoto Co., Suzuki-cho, Kawasaki, 210 (村井朝夫：味の素中 央研究所). 
$219^{\circ} \mathrm{C}$ (decomp.).

\section{Chemical Structure}

The molecular weight of teneraic acid was determined to be 173 from the parent peak as shown in Fig. 1. The elemental analysis of ammonium tenerate was $\mathrm{C}: 43.17, \mathrm{H}: 7.19, \mathrm{~N}: 14.15$, $\mathrm{O}: 33.19 \%$. The molecular formula was determined to be $\mathrm{C}_{7} \mathrm{H}_{11} \mathrm{~N}_{4} \mathrm{O}_{3}: \mathrm{NH}_{3}$ (calcd. C: 44.20 , $\mathrm{H}: 7.42, \mathrm{~N}: 14.32, \mathrm{O}: 33.65 \%$ ). The mass fragmentation pattern showed intense peaks at $m / e 128$ (M-COOH), $82\left(\mathrm{M}-\mathrm{C}_{2} \mathrm{H}_{3} \mathrm{O}_{4}\right)$ and $55\left(\mathrm{C}_{3} \mathrm{H}_{5} \mathrm{~N}\right.$ or $\mathrm{C}_{4} \mathrm{H}_{7}$ ). The NMR spectrum in $\mathrm{D}_{2} \mathrm{O}$ gave multiplet around $2 \mathrm{ppm}$ and triplet at $4.0 \mathrm{ppm}$ as shown in Fig. 2A. The multiplet could be identified as the six protons on three methylene groups in cyclic members. The triplet could be assigned to two protons on identical methine groups attached to both carboxyl and imino groups. The peaks $m / e$ 128 and 82 in Fig. 1 might be interpreted to be the following: $\mathrm{CH}_{2}-\mathrm{CH}_{2}-\mathrm{CH}_{2}-\mathrm{CH}(\mathrm{COOH})-\mathrm{NH}=\mathrm{CH}$ and $\mathrm{CH}_{2}-\mathrm{CH}_{2}-\mathrm{CH}=\mathrm{CH}-\mathrm{NH}=\mathrm{CH}$, respectively.

All above spectral data could be accommodated in the structure, piperidine-2,6-dicarboxylic acid for teneraic acid. The chemical structure of teneraic acid was confirmed by synthesis. Piperidine-2,6-dicarboxylic acid (2.4 g) obtained from catalytic hydrogenation of pyridine-2,6-dicarboxylic acid $(3 \mathrm{~g})$ gave the following elemental analysis, $\mathrm{C}: 44.15, \mathrm{H}: 6.88, \mathrm{~N}: 7.13 \%$; calcd. for $\mathrm{C}_{7} \mathrm{H}_{11} \mathrm{NO}_{4}: \mathrm{H}_{2} \mathrm{O}, \mathrm{C}: 44.98, \mathrm{H}: 6.81, \mathrm{~N}: 7.33 \%$. The imination reaction of $\alpha, \alpha^{\prime}$-dibromopimeric acid $(10 \mathrm{~g})$ gave two compounds by fractional crystallization. The first fraction $(1.1 \mathrm{~g})$ was

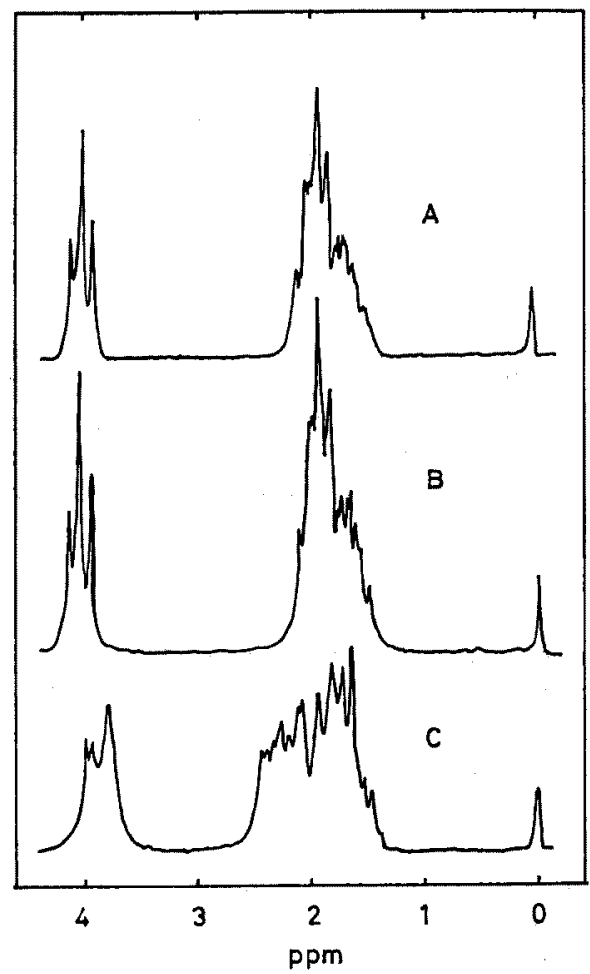

Fig. 2. NMR spectra of (A): teneraic acid, (B): piperidine-2,6-dicarboxylic acid (trans) (C): piperidine-2,6-dicarboxylic acid (cis) in $\mathrm{D}_{2} \mathrm{O}$ with DSS as standard.

analyzed to be the monohydrate which was identical to the compound obtained from the catalytic hydrogenation. The second fraction $(300 \mathrm{mg})$ was crystallized as the ammonium salt and gave an

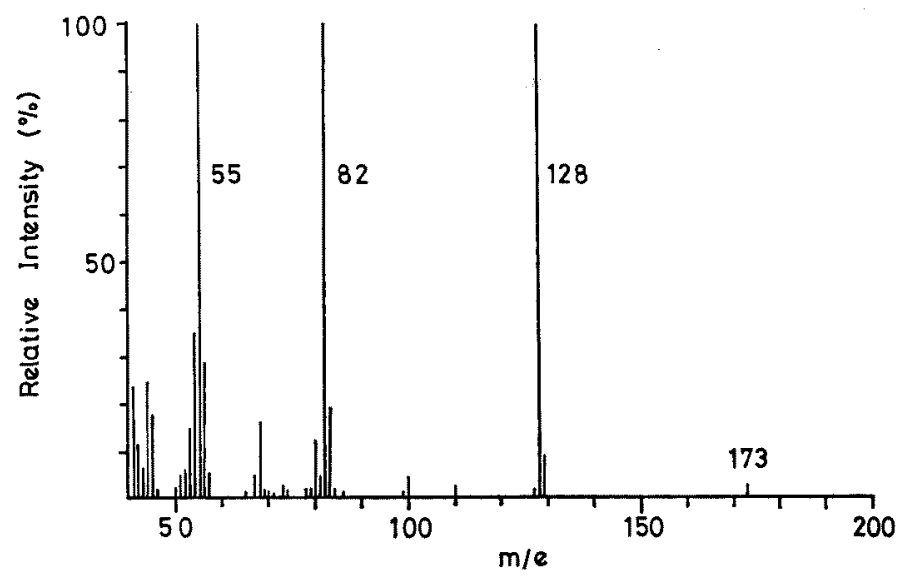

Fig. 1. Mass spectrum of teneraic acid. 


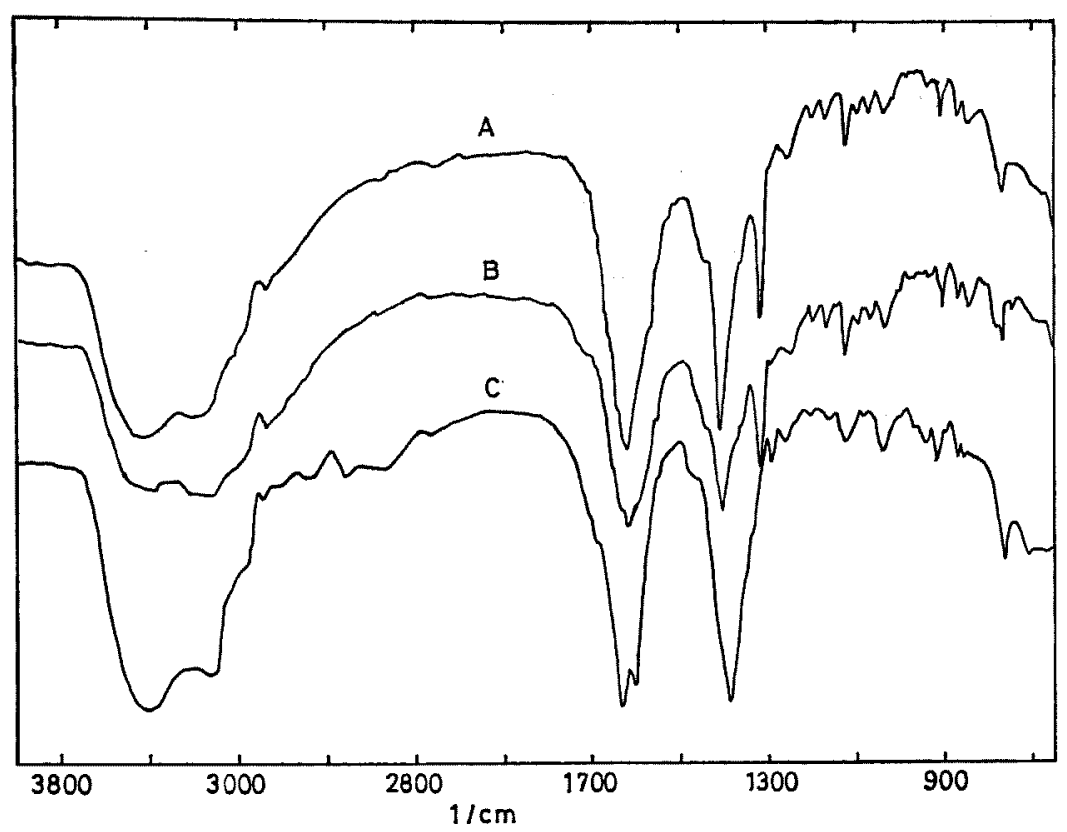

Fig. 3. IR spectra of ammonium salt of (A): teneraic acid, (B): piperidine-2,6-dicarboxylic acid (trans), (C): piperidine-2,6-dicarboxylic acid (cis) in $\mathrm{KBr}$ disc.

elemental analysis similar to that of ammonium tenerate.

All synthetic compounds and teneraic acid gave identical mass spectra. However, the synthetic piperidine-2,6-dicarboxylic acid monohydrate differed from teneraic acid in NMR (Fig. 2C) and IR spectrum (Fig. 3C) while the second fraction from the fractional crystallization of the piperidine-2,6dicarboxylic acid gave identical spectra to those of the natural compound as shown in Fig. 2B and 3B.

\section{Configuration}

Piperidine-2,6-dicarboxylic acid can exist as three isomers derived from two asymmetric carbons as shown in Fig. 4. It has been reported that the reduction of pyridine-2,6-dicarboxylic acid by platinium catalyst gives cis configuration only ${ }^{3}$, which is the meso form. Teneraic acid was optically active as shown in Fig. 5. Therefore, the con-<smiles>O=C(O)[C@@H]1CCC[C@](O)(C(=O)O)N1</smiles>

Fig. 4. Stereoisomers of piperidine-2,6-dicarboxylic acid. figuration can be assigned as a trans form. The native compound is either the $L(2 s, 6 s)$ or $D(2 R, 6 R)$ form, and is not a mixture. The assignment of the enantiomer is under investigation.

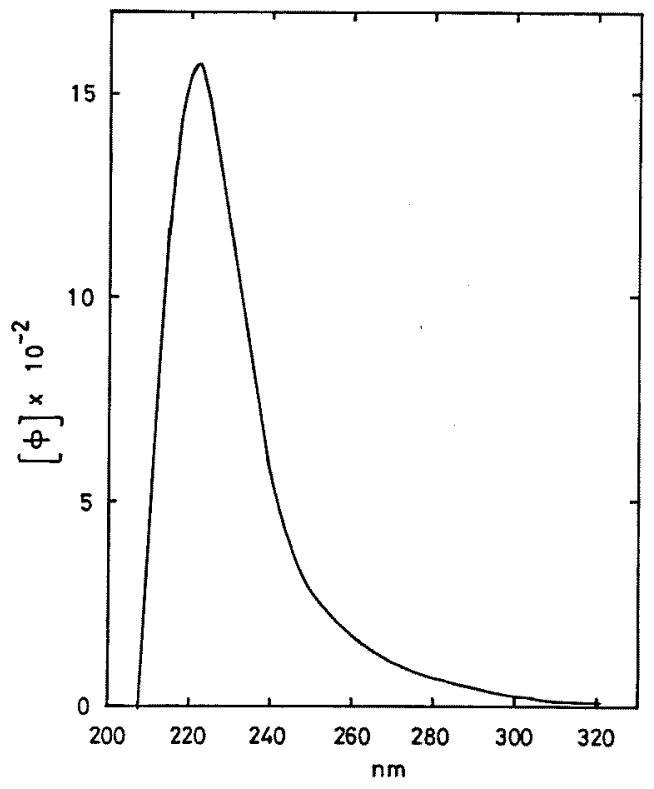

Fig. 5. ORD spectrum of ammonium tenerate in $\mathrm{H}_{2} \mathrm{O}$. 
This is the first publication of natural occurrence of piperidine-2,6-dicarboxylic acid (trans). Despite the relatively high yield $(120 \mathrm{mg} / \mathrm{kg}$ wet weight of the alga), the compound in an alcoholic extract could not be detected by amino acid analysis and paper chromatography because of the very low yield of ninhydrin color. It was detected on zone electrophoresis as very faint band with ninhydrin.

\section{Acknowledgement}

We are grateful to David Chung in Hormone Research Laboratory, University of California, San Francisco for the critical reading of this manuscript. This work was supported in part by Grant No. 266105 from the Ministry of Education.

\section{References}

1) H. Kawauchi, T. Kozuru, S. Ota, and T. Suzukr: Bull. Japan. Soc. Sci. Fish., 43, 12931297 (1977).

2) N. E. ANderson and T. O. SOINE: J. Am. Pharm. Assoc., 39, 460-462 (1950).

3) N. Campbell: in "Chemistry of Carbon Compound" (ed. by E. H. RoDD), Vol. 4 part A, Elsevier Publishing Co., Amsterdam, 1957, pp. 580-581. 